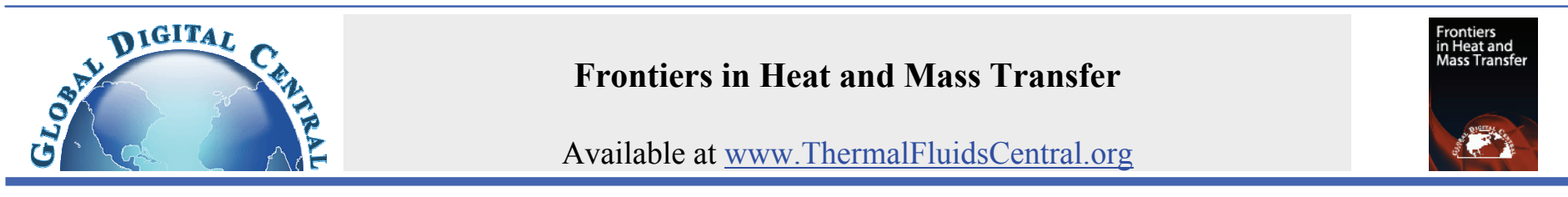

\title{
LAMINAR NATURAL CONVECTION STUDY IN A QUADRANTAL CAVITY USING HEATER ON ADJACENT WALLS
}

\author{
Dipak Sen*, Probir Kumar Bose, Rajsekhar Panua, Ajoy Kumar Das, Pulak Sen \\ Mechanical Engineering Department, National Institute of Technology, Agartala, Tripura, 799055, India
}

\begin{abstract}
A numerical analysis of laminar natural convection in a quadrantal cavity filled with water having variable length heaters attached on the adjacent walls have been made to examine heat and fluid flow. Numerical solutions are obtained using a commercial computational fluid dynamics package, FLUENT, using the finite volume method. Effects of the Rayleigh number, Ra, on the Nusselt number, Nu, as well as velocity and temperature fields are investigated for the range of Ra from $10^{3}$ to $10^{7}$. Computations were carried out for the non-dimensional heater lengths on the vertical wall $(\mathrm{m}=0.2,0.4$ and 0.6$)$ and horizontal wall $(\mathrm{n}=0.2,0.4$ and 0.6$)$. It is observed that heat transfer increases with increase in Rayleigh number and the flow strength increases with increase in size of heater on the vertical wall compared to the bottom wall and temperature fields are also affected. In contrast, with increase in size of heater on both side of adjacent walls flow strength does not changes significantly.
\end{abstract}

Keywords: Quadrantal cavity, heater, Rayleigh number, Nusselt number

\section{INTRODUCTION}

Natural convection in complex enclosures is an area of interest for several researchers. Simple square, rectangular or triangular cavities have been studied elaborately, but quadrantal enclosure has evoked considerable interest. This fact is amply reflected by the size of the research efforts during the past few decades dedicated to this topic. A detailed study of flow and heat transfer phenomena in quadrantal enclosures is useful in understanding the processes that occur in natural convection flows in building insulation materials, cooling of electrical equipments, solar collectors, geothermal applications, oil destruction etc.

The existing literature presents a vast number of studies on natural convection in enclosures. However, most of these studies have been related to either a vertically or a horizontally imposed heat flux or temperature difference. There is little work regarding natural convection in enclosures with heater used neighboring horizontal and vertical walls. Chu et al. (1976) investigated the effect of heater size, location, aspect ratio and boundary condition on two-dimensional, laminar, natural convection in rectangular channels both experimentally and numerically. They found that the maximum Nusselt number is obtained almost for all Rayleigh numbers when heater is located on the middle of the wall. In another study, Turkoglu and Yucel (1995) made a numerical study using control volume approach for the effect of heater and cooler locations on natural convection in cavities. They indicated that for a given cooler position; mean Nusselt number increases as the heater ismoved closer to the bottom horizontal wall. An experimental and numerical study of natural convection in a quadrantal cavity heated and cooled on adjacent walls was reported by Aydin and Yesiloz (2011a) and for inclined quadrantal cavity was reported by Aydin and Yesiloz (2011b). Chu and Hickox (1990) investigated the thermal convection with viscosity variation in a cavity with localized heating both experimentally and numerically. Besides these studies sometimes natural convection can be seen in cavities with discrete wall heat sources as indicated in Deng et al. (2002). Aydin et al. (1999) conducted a numerical study on buoyancy-driven laminar flow in an inclined square enclosure heated from one side and cooled from the adjacent side by using finite difference methods. In all of these studies, solution domain was chosen as square enclosure. Aydin and Yang (2000) studied the natural convection in an enclosure partially heated from the bottom wall and symmetrically cooled from the side walls. They observed that symmetrical flow fields are obtained when heater located at the centre of the bottom wall. Triangular shaped enclosures were investigated by some authors due to its shape is useful especially in the roof design or some of electronical devices. In the study of Asan and Namli (2001), the laminar natural convection heat transfer in triangular shaped roofs with different inclination angle and Rayleigh number in winter day conditions is investigated numerically using the finite volume method. They indicated that both aspect ratio and Rayleigh number affect the temperature and flow field. They also found that heat transfer decreases with the increasing of aspect ratio. Akinsete and Coleman (1982) illustrated the natural convection heat transfer in a triangular enclosure in steady-state regime. Moukalled andAcharya (2001) solved the governing equations of natural convection heat transfer inside a trapezoidal shaped geometry with baffles for building roofs in the conditions of summerlike and winter-like. They observed that in winter-like conditions, convection starts to dominate at a Rayleigh number much lower than that in summerlike conditions. Recently, Tzeng et al. (2005) proposed the Numerical Simulation Aided Parametric Analysis method to solve natural convection equations in streamline-vorticity form.

The aim of the present study is to investigate numerically the buoyancy-induced flow and heat transfer mechanisms in a water-filled quadrantal cavity from the heaters attached on both the vertical and horizontal walls, while curved wall is cold. To the best knowledge of the authors, this is the first natural convection study on this geometry with these boundary conditions.

\footnotetext{
*Corresponding Author Email: dipak_sen@ymail.com
} 


\section{PROBLEM DESCRIPTION}

A schematic diagram of the physical domain is shown in Fig.1. A portion of both the vertical and the bottom wall is composed of heaters, the rest portion comprises of the adiabatic walls. The length of the heaters in the vertical and the horizontal wall is represented by nondimensional number $\mathrm{m}$, the ratio of length of heater and length of vertical wall and $n$, the ratio of length of heater and length of horizontal wall respectively. The curved wall is considered as the cold wall. The flow is assumed to be steady and laminar. Constant fluid properties are assumed, except for the density changes with temperature that induce buoyancy forces, so the Boussinesq approximation is adopted.

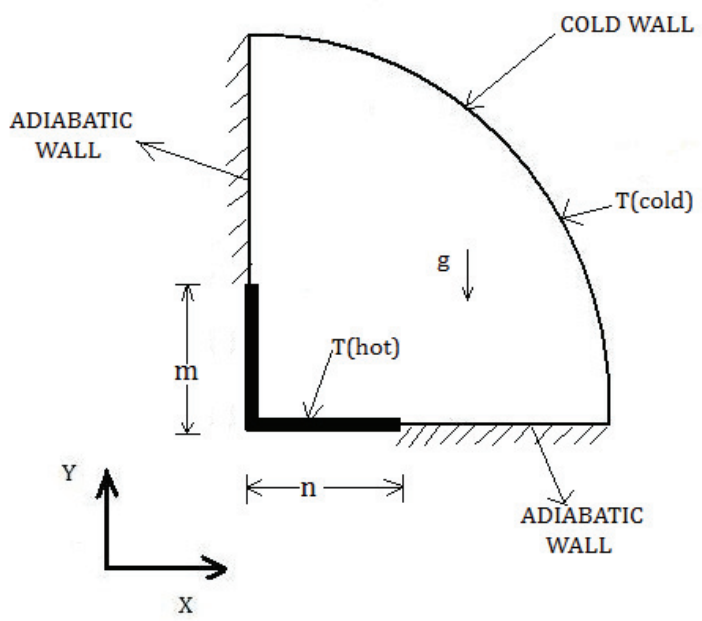

Fig.1 Schematic diagram of the physical domain

\section{GOVERNING EQUATIONS}

The continuity, momentum and energy equations for a two dimensional laminar flow of an incompressible Newtonian fluid is considered. Following assumptions are made: there is no viscous dissipation, the cavity walls are impermeable, the gravity acts in negative y-direction, fluid properties are constant and fluid density variations are neglected except in the buoyancy term (the Boussinesq approximation) and radiation heat exchange is negligible. Using non-dimensional variables defined in the nomenclature, the non-dimensional governing equations are obtained as:

$$
\begin{aligned}
& \frac{\partial U}{\partial X}+\frac{\partial V}{\partial Y}=0 \\
& U \frac{\partial U}{\partial X}+V \frac{\partial U}{\partial Y}=-\frac{\partial P}{\partial X}+\operatorname{Pr}\left(\frac{\partial^{2} U}{\partial X^{2}}+\frac{\partial^{2} U}{\partial Y^{2}}\right) \\
& U \frac{\partial V}{\partial X}+V \frac{\partial V}{\partial Y}=-\frac{\partial P}{\partial Y}+\operatorname{Pr}\left(\frac{\partial^{2} V}{\partial X^{2}}+\frac{\partial^{2} V}{\partial Y^{2}}+R a \operatorname{Pr} \theta\right) \\
& U \frac{\partial \theta}{\partial X}+V \frac{\partial \theta}{\partial Y}=\frac{\partial^{2} \theta}{\partial X^{2}}+\frac{\partial^{2} \theta}{\partial Y^{2}}
\end{aligned}
$$

Appearing in Eqs. (2) and (3), Pr and Ra are the Prandtl and Rayleigh numbers, respectively, which are defined as

$$
\operatorname{Pr}=\frac{v}{\alpha}, R a=\frac{g \beta H^{3}\left(T_{h}-T_{C}\right)}{v \alpha}
$$

where $\beta$ and $v$ are the thermal expansion coefficient and the kinematic viscosity of the fluid, respectively.
The non-dimensional parameters are listed as

$$
\begin{aligned}
& X=\frac{x}{H}, Y=\frac{y}{H}, U=\frac{u}{\alpha / H}, V=\frac{v}{\alpha / H}, P=\frac{p H^{2}}{\rho \alpha^{2}} \\
& \theta=\frac{T-T_{C}}{T_{h}-T_{C}}
\end{aligned}
$$

\subsection{Boundary conditions}

Through the introduction of the non-dimensional parameters into the physical boundary conditions illustrated in Fig. 1, the following nondimensional boundary conditions are obtained:

On the curved wall

$\theta=0, \mathrm{U}=\mathrm{V}=0$ at $0<\mathrm{X}<1$ and $0<\mathrm{Y}<1$

On the bottom wall,

For the heater part:

$\theta=1, \mathrm{U}=\mathrm{V}=0$ at $\mathrm{Y}=0$ and $0<\mathrm{X}<\mathrm{n}$

For the adiabatic part:

$$
\frac{\partial \theta}{\partial Y}=0, \mathrm{U}=\mathrm{V}=0 \text { at } \mathrm{Y}=0 \text { and } \mathrm{n}<\mathrm{X}<1
$$

On the vertical wall,

For the heater part:

$\theta=1, \mathrm{U}=\mathrm{V}=0$ at $\mathrm{X}=0$ and $0<\mathrm{Y}<\mathrm{m}$

For the adiabatic part:

$\frac{\partial \theta}{\partial X}=0, \mathrm{U}=\mathrm{V}=0$ at $\mathrm{X}=0$ and $\mathrm{m}<\mathrm{X}<1$

\section{NUMERICAL APPROACH}

The continuity, momentum and the energy equations are solved using commercially available software FLUENT 6.3. Discretization of the momentum and energy equations is performed by a second order upwind scheme and pressure interpolation is provided by PRESTO scheme. Convergence criterion considered as residuals is admitted $10^{-3}$ for momentum and continuity equations and for the energy equation it is $10^{-6}$. In this study, the mesh is structured in such a way that the path of the heat lines, which intersect the isotherms spanning orthogonally from the isothermal hot bottom wall to the isothermal cold curved wall for the conduction solution, is considered.

The Nusselt number along the hot wall can be defined as

$$
N u_{r}=\frac{q r}{k\left(T_{\text {hot }}-T_{\text {cold }}\right)} \frac{\pi}{2}
$$

Thus, we calculated Nusselt number manually using the Eq. (12).

\subsection{Grid independency test}

In the study, four different mesh sizes $(40 \times 40,60 \times 60,80 \times 80$ and $100 \times 100)$ are adopted in order to check the mesh independence. A detailed grid independence study has been performed, and results are 
obtained for the average Nusselt number, and the maximum values of the stream function, but any considerable changes were not obtained. Thus, a grid size of $80 \times 80$ is found to meet the requirements of both the grid independency study and the computational time limits.

Table 1 Relative error analysis with different grid sizes $\left(\mathrm{T}_{\mathrm{h}}=279.2 \mathrm{~K}\right.$, $\mathrm{T}_{\mathrm{c}}=278.8 \mathrm{~K}, \mathrm{Ra}=10^{4}$ )

\begin{tabular}{|c|c|c|c|c|}
\hline MESH SIZE & $40 \times 40$ & $60 \times 60$ & $80 \times 80$ & $100 \times 100$ \\
\hline$\Psi_{\mathrm{MAX}}$ & 2.01 & 2.0106 & 2.0263 & 2.0296 \\
\hline $\begin{array}{l}\text { RELATIVE } \\
\text { ERROR(\%) }\end{array}$ & \multicolumn{2}{|c|}{0.0298} & \multicolumn{2}{|c|}{0.33} \\
\hline $\mathrm{Nu}$ (avg) & 5.9812 & 6.5737 & 7.1706 & 7.607 \\
\hline $\begin{array}{l}\text { RELATIVE } \\
\text { ERROR(\%) }\end{array}$ & 9.1 & 8.3 & \multicolumn{2}{|c|}{5.737} \\
\hline
\end{tabular}

\subsection{Validation}

Due to lack of suitable results in the literature pertaining to the present configuration, the result obtained have been validated against the existing results for a quadrantal cavity filled with water medium when the bottom wall is heated and the vertical wall is cold (Aydin and Yesiloz, 2011a). Figures 2 and 3 indicate that the result showed good agreement with the literature. However, the published experimental results are not available for the enclosure configuration similar to that undertaken in this study with similar boundary conditions.
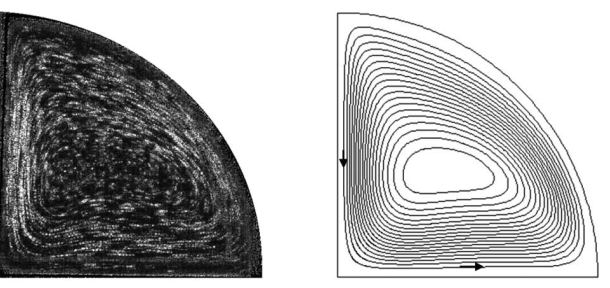

$\Psi_{\max }=21.09$

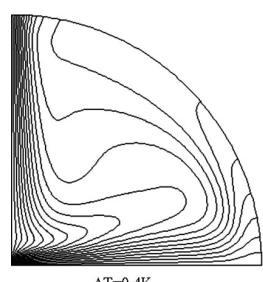

$\Delta \mathrm{T}=0.4 \mathrm{~K}$
Fig. 2 Experimental (left) and numerical (right) streamline and isotherm for $\mathrm{Ra}=1.7 \times 10^{5}$ from Aydin and Yesiloz (2011a).
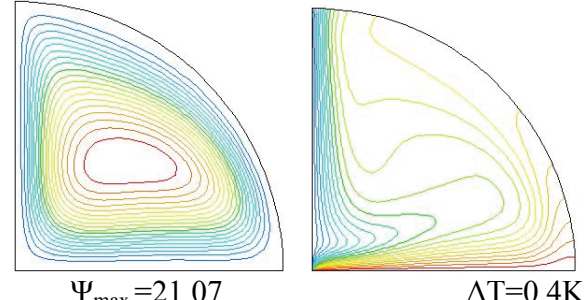

Fig. 3 Numerical results from present study: streamline and isotherm for $\mathrm{Ra}=1.7 \times 10^{5}$

\section{RESULTS AND DISCUSSIONS}

Numerical analysis of laminar natural convection heat transfer and fluid flow is performed to obtain effects of Rayleigh number in an enclosure which is heated by the heaters attached in both the horizontal and vertical walls. The curved wall is assumed as the cold wall i.e. it has temperature less than that of the heater. The portion of the heaters in both the bottom and the vertical wall has higher temperature. The part on the bottom and the vertical wall other than the heater is considered as adiabatic. Results of flow fields and temperature distribution for different Rayleigh numbers, $R a$, dimensionless length of heater in the vertical wall $\mathrm{m}$, dimensionless length of fin on the bottom wall $\mathrm{n}$, were plotted in this part of the study. Dimensionless length of the heater on the vertical wall varied as $0.2,0.4$ and 0.6 . Also, dimensionless length of the thin fin on the bottom wall varied as $0.2,0.4$ and 0.6 . The range of the Rayleigh number, $R a$, was taken as $10^{4}$ to $10^{7}$.

Figures 4 and 5 show the streamlines and isotherms for different Rayleigh numbers at $m=0.2$ and $n=0.2$ to 0.6 . As the value of $R a$ number is increased to $5 \times 10^{6}$ or more, two cells are formed on the top and mid-bottom part of the enclosure in anti-clock and clockwise direction respectively. No marked difference in streamline pattern takes place for a particular Rayleigh number having different geometries in heater size. As there is no obstruction of flow inside the quadrantal cavity, the heat transfer from the heaters to the cold curved wall occurs by buoyancy phenomena. With higher values of Rayleigh number there is crowding of streamlines on the vertical walls indicating boundary layer formation. The static temperature diagram shows concentration of isotherms near the cool curved wall, suggesting that heat transfer rate is high near the vicinity of the curved wall. Less packed isotherms are formed in the central part of the enclosure that indicates lower heat transfer. At the lowest Rayleigh number $\left(R a=10^{4}\right)$, a relatively weak convective flow exists in the quadrantal cavity. As the Rayleigh number increases, the elliptical centre shifts towards the vertical wall and also the size of the elliptical centre increases along with the deformation of the elliptical centre. With Rayleigh numbers of $5 \times 10^{6}$ and more, there are two cell generated inside the closed enclosure. Isotherms show almost the same pattern for all Rayleigh numbers. Effects of the presence of heater on isotherms become stronger as the Rayleigh number increases. For lower Rayleigh numbers, the convection intensity in the enclosure is very weak as evident from the values of the stream functions. It means that the viscous forces are more dominant than the buoyancy forces at lower $R a$ numbers.

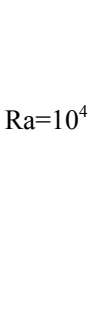

$\mathrm{Ra}=1.7 \times 10^{5}$
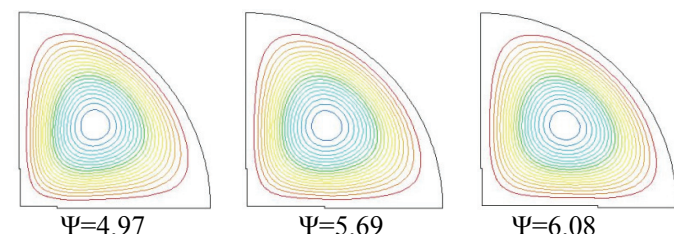

$\Psi=5.69$

$\Psi=6.08$
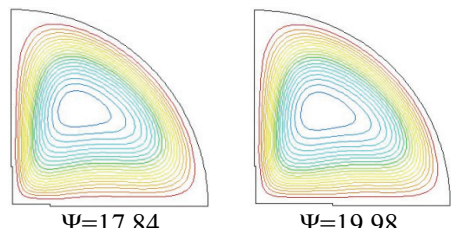

$\Psi=19.98$

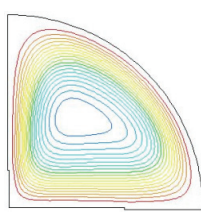

$\Psi=21.96$
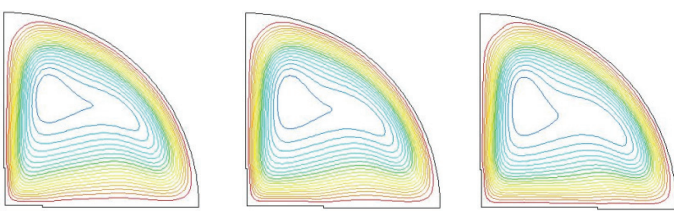

$\Psi=30.94$

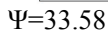

$\Psi=36.55$
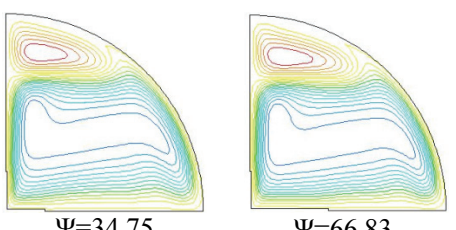

$\Psi=66.83$

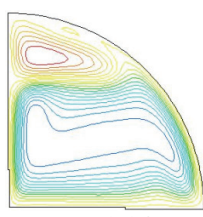

$\Psi=70.94$
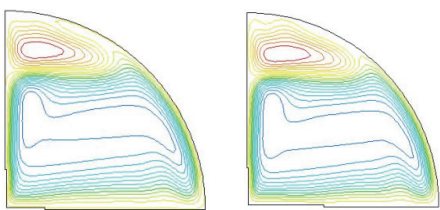

$\Psi=83.15$

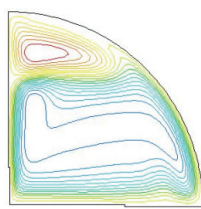

$\Psi=89.77$

Fig. 4 Streamlines for dimensionless heater length, $m=0.2$, columnwise different dimensionless heater lengths, $\mathrm{n}=0.2, \mathrm{n}=0.4$, $\mathrm{n}=0.6$. 

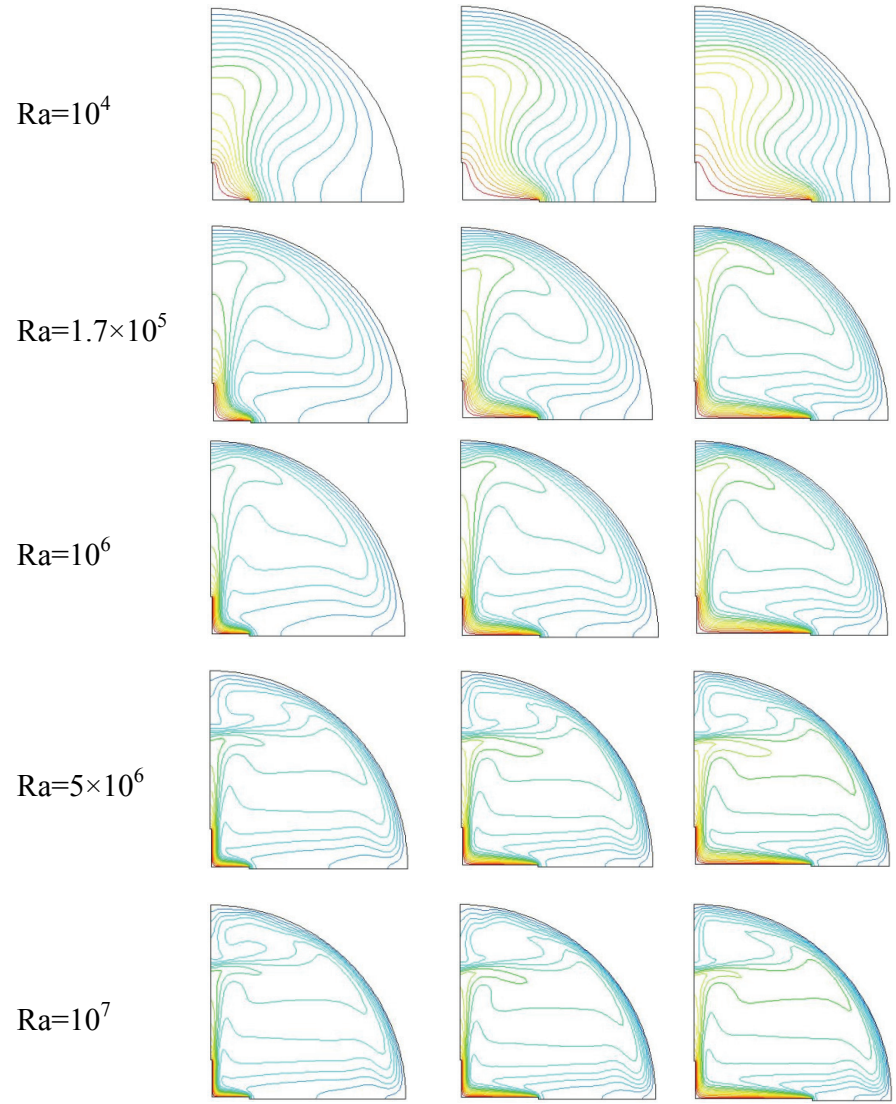

Fig. 5 Isotherms for dimensionless heater length, $m=0.2$, column-wise different dimensionless heater lengths, $\mathrm{n}=0.2, \mathrm{n}=0.4, \mathrm{n}=0.6$.

Different length of heaters are given in Figs. 6 and 7 for $R a=10^{4}$ to $10^{7}, \mathrm{n}=0.2$ and $\mathrm{m}=0.2,0.4$ and 0.6. At the lowest Rayleigh number $\mathrm{Ra}=10^{4}$, streamlines form a nearly centrally located single cell forming an elliptical shape, and corresponding isotherms exhibit the characteristics of quasi-conduction. The hot fluid layer heated around the heater ascends upward by reason of decreasing density and the weak circulation in the enclosure. On the other hand, nearby the curve wall, the fluid layer with increased density moving downward sweeps the hot fluid layer forward. Since the curved wall is the cool wall, the hot fluid here exchanges heat with the cool curved wall and the cooler fluid here forms a cold fluid layer. These mutual effects of the hot and cold fluid layers cause isotherms to widen. Further increases in Rayleigh number, recirculation intensity increases to a degree that boundary layer formations are observed adjacent to the heater surface and cooled walls. The heated flow impinges to the curved wall to exchange heat. For the all configurations of the heater i.e. $\mathrm{n}=0.2$ and $\mathrm{m}=0.2,0.4$ and 0.6 , an elliptical shape single cell has formed at the lowest Rayleigh number Ra $=10^{4}$. As increases in the Rayleigh numbers two cells are formed and also boundary layer formation occurs near the top portion of the enclosure and the cavity is divided into two parts. The isotherm plots are concentrated towards the curved wall.

Figures 8 and 9 shows the streamlines and isotherms for different Rayleigh numbers at $\mathrm{m}=0.2, \mathrm{n}=0.2 ; \mathrm{m}=0.4, \mathrm{n}=0.4$ and $\mathrm{m}=0.6, \mathrm{n}=0.6$. For the case of $m=0.6$ and $n=0.6$, the stream lines gets crowded near the bottom and the vertical surface with the increase in Rayleigh number thus causing boundary layer formation near the horizontal and the vertical walls. The isotherms form the above case is also crowded near the heater surface and the curved wall. This indicates that maximum heat transfer takes place in the vicinity of the heater surface and also the near the cold curved wall surface.

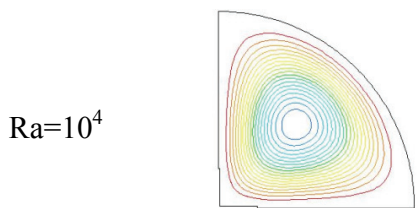

$\Psi=4.97$

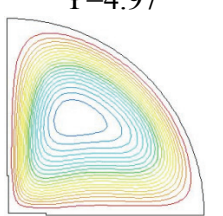

$\Psi=17.84$

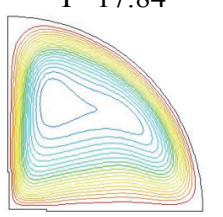

$\Psi=30.94$

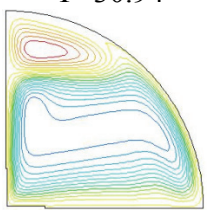

$\Psi=34.75$

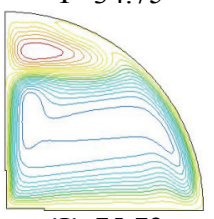

$\Psi=75.72$

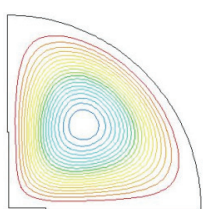

$\Psi=5.45$

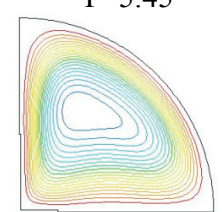

$\Psi=18.16$

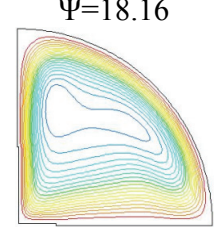

$\Psi=30.06$

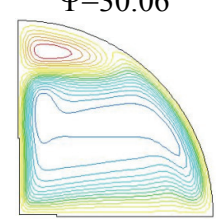

$\Psi=60.04$

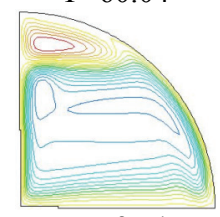

$\Psi=73.71$

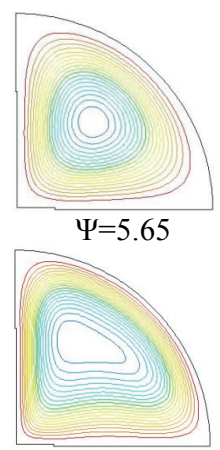

$\Psi=17.66$

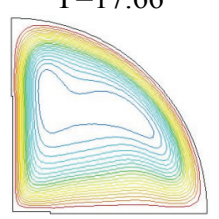

$\Psi=28.32$

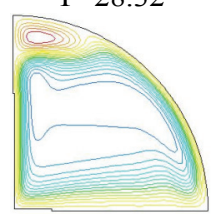

$\Psi=53.27$

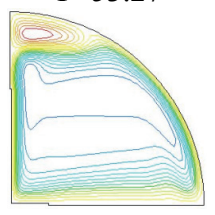

$\Psi=67.10$
Fig. 6 Streamlines for dimensionless heater length, $n=0.2$, column wise different dimensionless heater lengths, $\mathrm{m}=0.2, \mathrm{~m}=0.4, \mathrm{~m}=0.6$

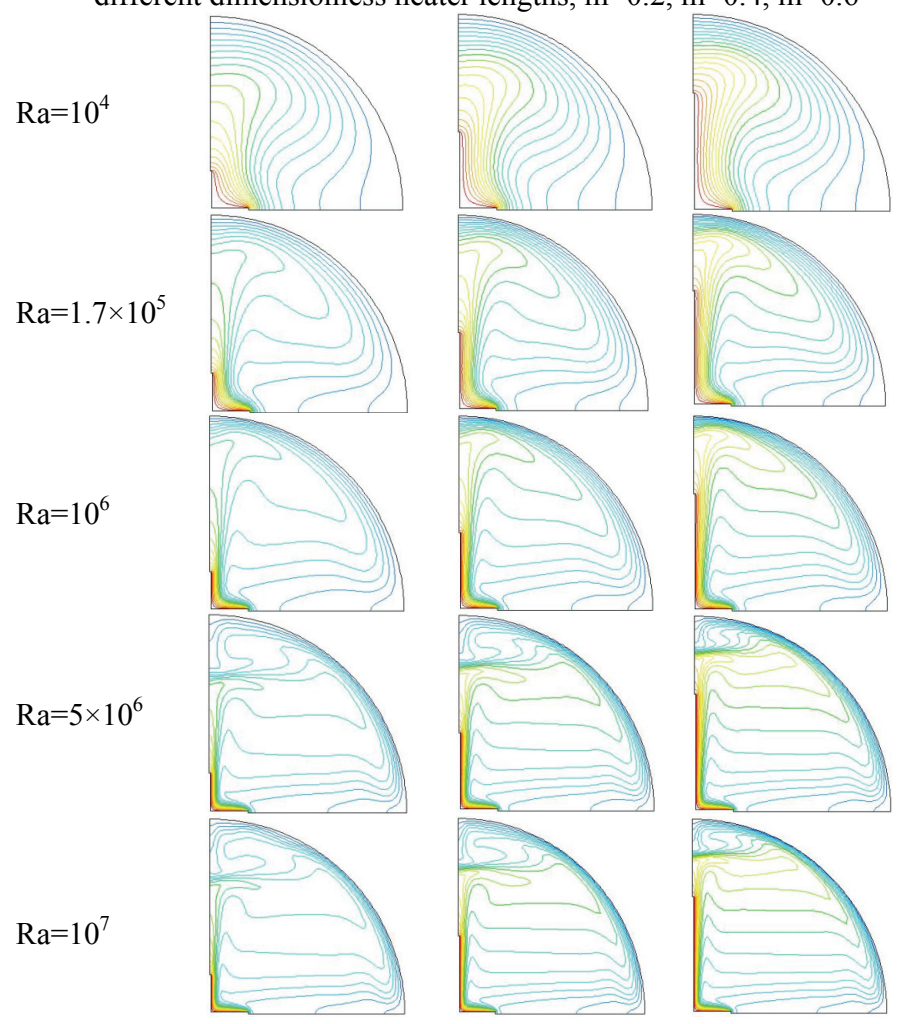

Fig. 7 Isotherms for dimensionless heater length, $\mathrm{n}=0.2$, column wise different dimensionless heater lengths, $\mathrm{m}=0.2, \mathrm{~m}=0.4, \mathrm{~m}=0.6$. 


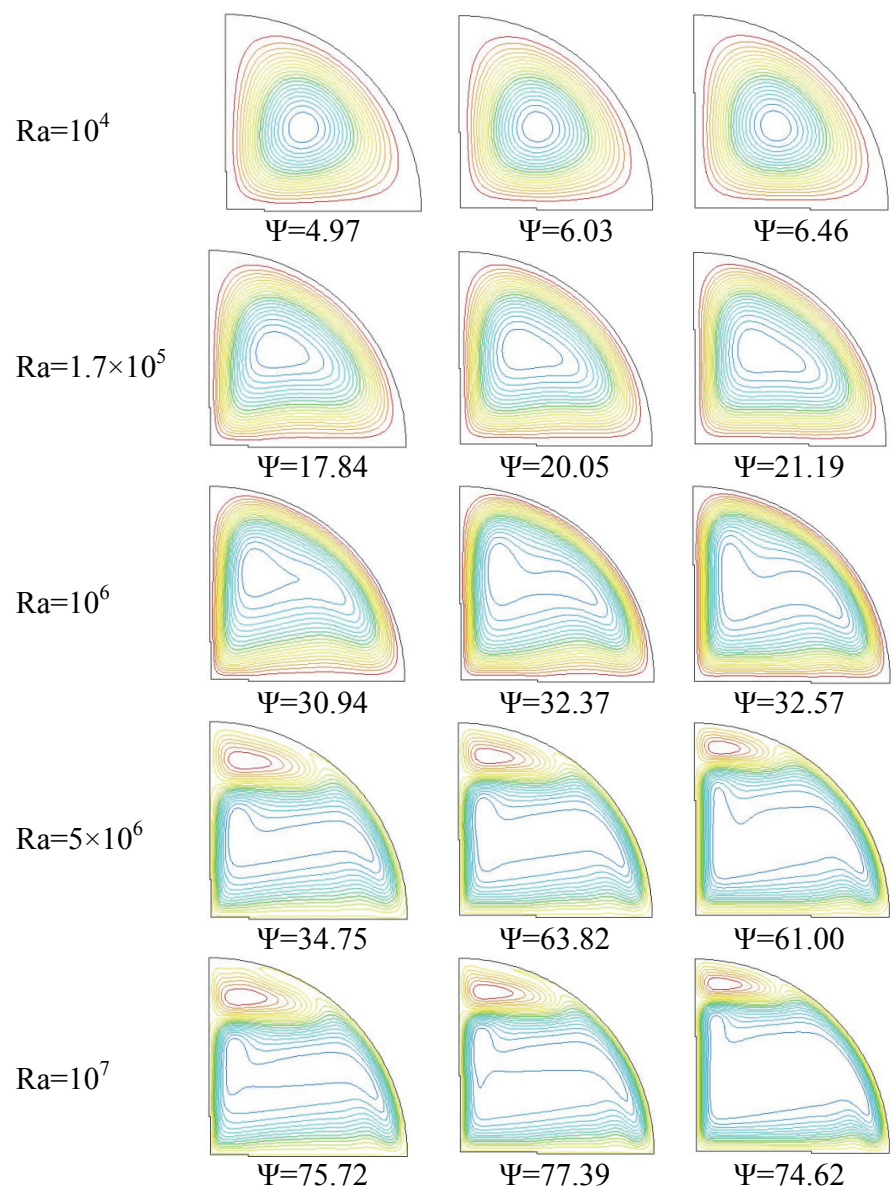

Fig. 8 Streamlines, column wise different dimensionless heater lengths, $\mathrm{m}=0.2, \mathrm{n}=0.2 ; \mathrm{m}=0.4, \mathrm{n}=0.4 ; \mathrm{m}=0.6, \mathrm{n}=0.6$.

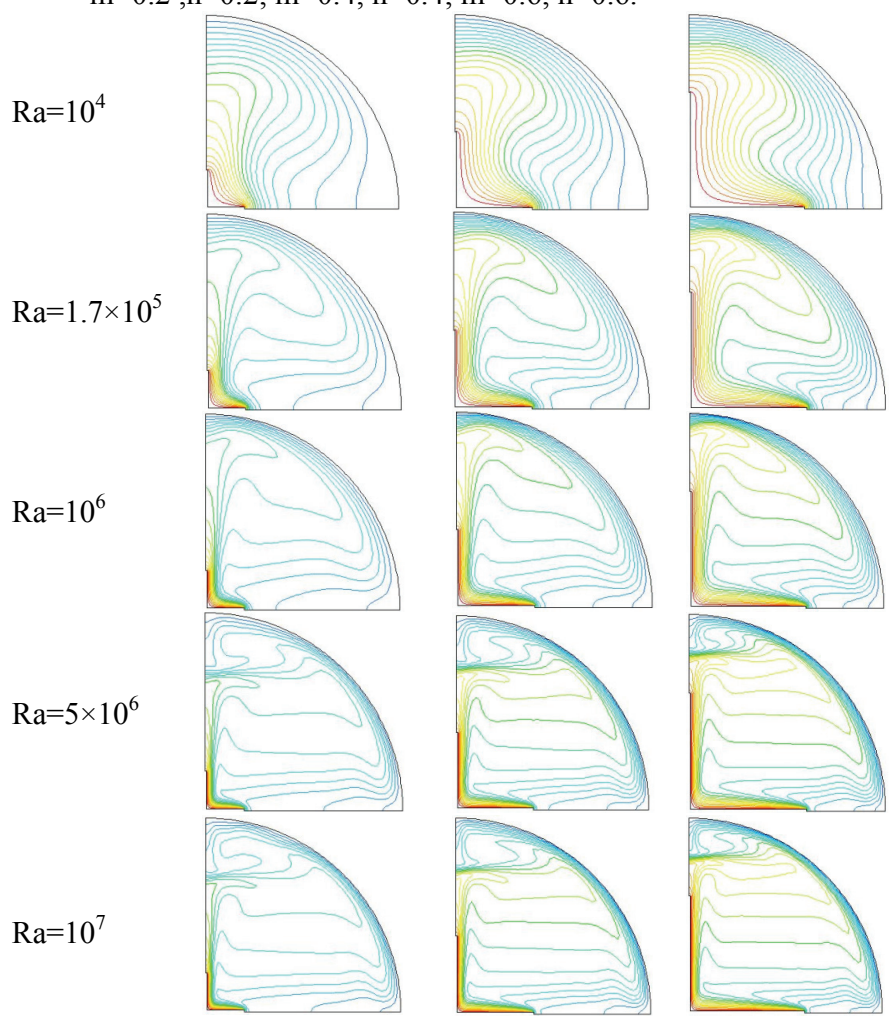

Fig. 9 Isotherms, column wise different dimensionless heater lengths, $\mathrm{m}=0.2, \mathrm{n}=0.2 ; \mathrm{m}=0.4, \mathrm{n}=0.4 ; \mathrm{m}=0.6, \mathrm{n}=0.6$.
Figure 10 shows the effect of dimensionless lengths of heater on the Nusselt number. The dimensionless heater length on the vertical wall is kept constant while that of the bottom horizontal wall is varied from 0.2, 0.4 and 0.6. It can be observed that for low $\mathrm{Ra}$, the $\mathrm{Nu}$ for the three cases is very close. But as Ra increases, there is a large variation in the $\mathrm{Nu}$. And when the heater length is the smallest, the value of $\mathrm{Nu}$ is minimum.

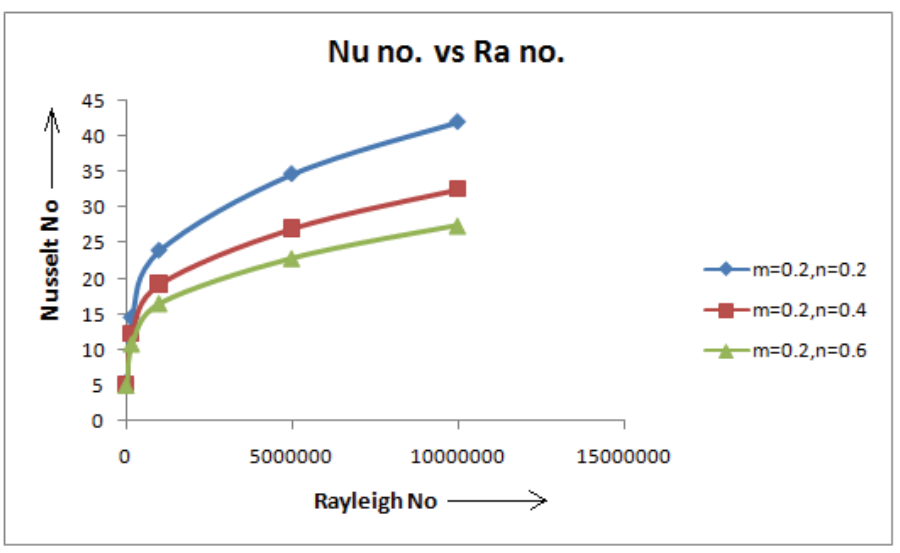

Fig. 10 Variation of mean $\mathrm{Nu}$ no. with Rayleigh number $\left(10^{4}\right.$ to $\left.10^{7}\right)$ for different heater lengths $(\mathrm{n}=0.2,0.4,0.6)$ for $\mathrm{m}=0.2$.

Figure 11 is the case when the non-dimensional heater length on the bottom horizontal wall is kept constant at 0.2 and that of the vertical wall is varied from $0.2,0.4$ and 0.6. Similar to the above case the value of $\mathrm{Nu}$ for low $\mathrm{Ra}$ is almost same for the three cases due to the quasistatic regime, but $\mathrm{Nu}$ becomes stronger as the Rayleigh number increases.

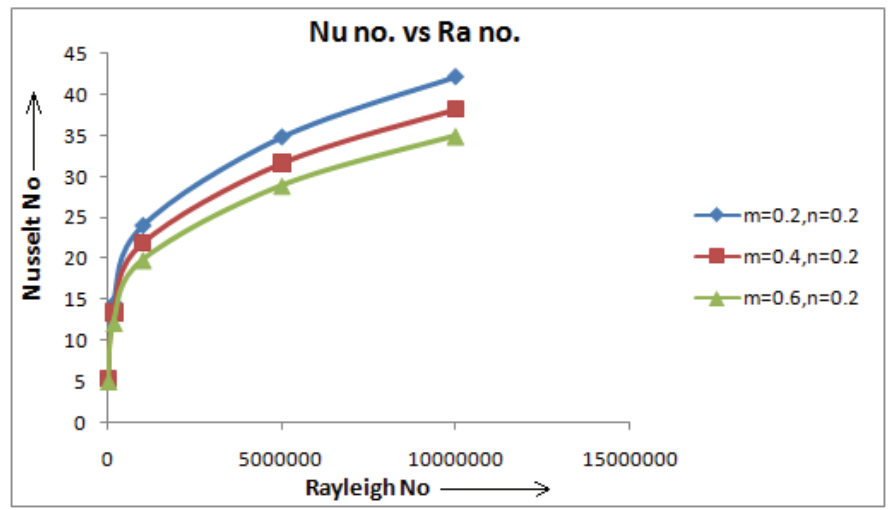

Fig. 11 Variation of mean $\mathrm{Nu}$ no. with Rayleigh number $\left(10^{4}\right.$ to $\left.10^{7}\right)$ for different heater lengths $(m=0.2,0.4,0.6)$ for $n=0.2$.

Figure 12 represents our third study case where the increment in the non-dimensional heater lengths in both the horizontal and the vertical wall is same. From the Fig. 10, 11 and 12, it is observed that the deviation of Nusselt number depends on the non-dimensional lengths of the heaters. If the non-dimensional length of the heater on the vertical wall is more than or that on the bottom wall then the Nusselt number is high compared to cases where the length of heater on the vertical wall is less or equal to that of the bottom wall. The Nusselt number is also high for the cases when the non-dimensional lengths of the heater on both the wall is small, and it decreases with the simultaneous increase in the heater lengths. 


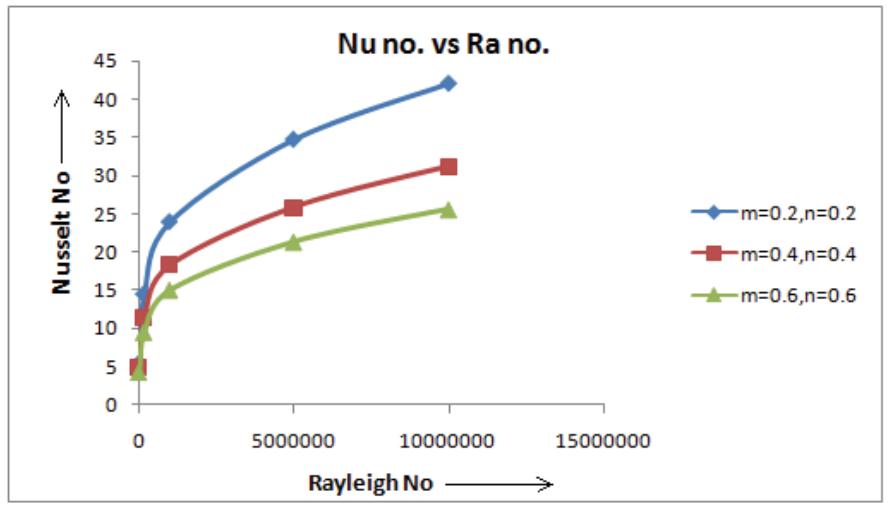

Fig. 12 Variation of mean $\mathrm{Nu}$ no. with Rayleigh number $\left(10^{4}\right.$ to $\left.10^{7}\right)$ for different heater lengths $(\mathrm{m}=0.2, \mathrm{n}=0.2 ; \mathrm{m}=0.4, \mathrm{n}=0.4 ; \mathrm{m}=0.6, \mathrm{n}=0.6)$

\section{CONCLUSIONS}

Numerical study has been performed to analyze the flow and temperature fields as well as the heat transfer rate on laminar natural convection in quadrentral cavity filled with water having heaters of varying lengths on both the vertical wall and the bottom wall. The curved wall is taken as the cold wall. The effects of Rayleigh number $\left(10^{4}\right.$ to $\left.10^{7}\right)$, non-dimensional heater lengths on the vertical wall $(\mathrm{m}=0.2,0.4$ and 0.6$)$ and horizontal wall $(\mathrm{n}=0.2,0.4$ and 0.6$)$ is studied.

The result of the numerical analysis lead to the following conclusions:-

1) Heat transfer increases with increase in Rayleigh number.

2) With smaller heater lengths, higher heat transfer is achieved at higher Rayleigh numbers. At small Rayleigh numbers the heat transfer is almost same irrespective of heater lengths.

3) With increase in the non-dimensional heater length on the vertical wall, the heat transfer decreases comparative with small heater lengths. This decrease in heat transfer is less if the heater length on the bottom wall is small and becomes drastic for larger lengths of the bottom heater.

4) As the non-dimensional length of the heater in the bottom wall is increased, the heat transfer decreases comparatively with lower heater lengths for the same Rayleigh number irrespective of the change in the heater lengths of the vertical wall.

\section{NOMENCLATURE}

Ra Rayleigh number

$\mathrm{Nu} \quad$ Nusselt number

$T \quad$ Temperature

Pr Prandtl number

$H \quad$ enclosure height

$p \quad$ pressure

$P \quad$ non-dimensional pressure

$\mathrm{k} \quad$ thermal conductivity

$q \quad$ heat flux

$c_{p} \quad$ specific heat

$u$

$v$

velocity component in the $\mathrm{x}$-direction

velocity component in the v-direction

non-dimensional velocity component in the $\mathrm{x}$-direction non-dimensional velocity component in the y-direction Cartesian coordinate system

non-dimensional coordinates

cylindrical coordinate system

non-dimensional heater length on vertical wall, $\mathrm{m}$ '/L non-dimensional heater length on horizontal wall, n'/L

$\begin{array}{ll}\psi & \text { stream function } \\ \Psi & \text { non-dimensional stream function, } \psi / \alpha \\ \rho & \text { density } \\ \beta & \text { co-efficient of thermal expansion } \\ v & \text { kinematic viscosity } \\ \alpha & \text { Thermal diffusivity } \\ \mu & \text { dynamic viscosity } \\ \theta & \text { dimensionless temperature } \\ & \\ \text { Subscripts } & \\ h & \text { hot wall } \\ \text { c } & \text { cold wall } \\ \text { max } & \text { maximum } \\ \text { min } & \text { minimum }\end{array}$

\section{REFERENCES}

Akinsete, V.A., and Coleman, T.A., 1982, "Heat Transfer by Steady Laminar Free Convection in Triangular Enclosures," International Journal of Heat and Mass Transfer, 25, 991-998. http://dx.doi.org/10.1016/0017-9310(82)90074-6

Asan, H., and Namli, L., 2001, "Numerical Simulation Of Buoyant Flow In A Roof Of Triangular Cross Section Under Winter Day Boundary Conditions," Energy and Buildings, 33, 753-757. http://dx.doi.org/10.1016/S0378-7788(01)00063-9

Aydin, O., Unal, A., and Ayhan, T., 1999, "A Numerical Study On Buoyancy-driven Flow in an Inclined Enclosure Heated and Cooled on Adjacent Walls," Numerical Heat Transfer Part A: Applications, 36, 585-589.

http://dx.doi.org/10.1080/104077899274589

Aydin, O., and Yesiloz, G., 2011a, "Natural Convection in a Quadrantal Cavity Heated and Cooled on Adjacent Walls," ASME Journal of Heat Transfer, 133, 052501-7.

http://dx.doi.org/10.1115/1.4003044

Aydin, O., and Yesiloz, G., 2011b, "Natural Convection in an inclined Quadrantal Cavity Heated and Cooled on Adjacent Walls," Experimental Thermal and Fluid Science, 35, 1169-1176. http://dx.doi.org/10.1016/j.expthermflusci.2011.04.002

Aydin, O., and Yang, W.J., 2000, "Natural Convection in Enclosures with Localized Heating from Below and Symmetrical Cooling From Sides," International Journal of Numerical Methods for Heat and Fluid Flow, 10, 518-529.

http://dx.doi.org/10.1108/09615530010338196

Chu, H.H.S., Churchill, S.W., and Patterson, C.V.S., 1976, "The Effect of Heater Size, Location, Aspect Ratio, and Boundary Conditions on Two-Dimensional Laminar, Natural Convection in Rectangular Channels," ASME Journal of Heat Transfer, 98, 1194-1201. http://dx.doi.org/10.1115/1.3450518

Chu, T.Y., and Hickox, C.E., 1990, "Thermal Convection with Large Viscosity Variation in an Enclosure with Localized Heating," ASME Journal of Heat Transfer, 112, 388-395.

http://dx.doi.org/10.1115/1.2910389

Deng, Q.H., and Tang, G.F., 2002, “A Combined Temperature Scale for Analyzing Natural Convection in Rectangular Enclosures with Discrete Wall Heat Sources," International Journal of Heat and Mass Transfer, 45, 3437-3446.

http://dx.doi.org/10.1016/S0017-9310(02)00060-1

Deng, Q.H., Tang, G.F., Li, Y., and Ha, M.Y., 2002, "Interaction between Discrete Heat Sources in Horizontal Natural Convection Enclosures," International Journal of Heat and Mass Transfer, 45, $5117-5132$.

http://dx.doi.org/10.1016/S0017-9310(02)00221-1 
FLUENT User's Guide, Release 6.3.26, Fluent Incorporated (2005-0106).

Moukalled, F., and Acharya, S., 2001, "Natural Convection in Trapezoidal Enclosure with Offset Baffles," Journal of Thermophysics and Heat Transfer, 15, 212-218.

http://dx.doi.org/10.2514/2.6596
Turkoglu, H., and Yucel, N., 1995, "Effect of Heater and Cooler Locations on Natural Convection in Square Cavities," Numerical Heat Transfer Part A: Applications, 27, 351-358.

http://dx.doi.org/10.1080/10407789508913705

Tzeng, S.C., Liou, J.H., and Jou, R.Y., 2005, "Numerical SimulationAided Parametric Analysis of Natural Convection in a Roof of Triangular Enclosures," Heat Transfer Engineering, 26, 69-79. http://dx.doi.org/10.1080/01457630591003899 